\title{
LEIDEN V FACTOR AND METHYLEN TETRAHYDROFOLATE REDUCTASE ENZYME GENE MUTATIONS IN PRIMIGRAVIDAS WITH MISSED ABORTION IN LATE FIRST TRIMESTER: CROSS-SECTIONAL STUDY
}

\author{
nermeen hefila ${ }^{1}$, nermeen elbeltagy ${ }^{1}$, mohamed $\operatorname{rizk}^{1}$, and doaa mohamed ${ }^{1}$ \\ ${ }^{1}$ Alexandria University
}

October 1, 2020

\begin{abstract}
ABSTRACT Nowadays, thrombophilia is one of the leading causes of RPL which has negative side effects due to psychological effect and the high expenses of investigations and attempts to get normal full term pregnancy up to ICSI trials in some cases. So as early as possible we try to diagnose the cause of abortion and treat it to avoid another bad experience of abortion. Aim of the work: to evaluate the correlation of factor V Leiden and MTHFR C677T gene mutation in primigravida late first trimester abortion and to identify candidates for anticoagulation therapy to improve pregnancy outcome .METHODOLOGY: polymerase chain reaction (PCR) and reverse-hybridization were used to assess MTHFR and FV leiden mutations . Results: MTHFR C $677 \mathrm{~T}$ mutations were $42.5 \%$. While factor V leiden gene mutation were $20 \%$. Combined MTHFR C $677 \mathrm{~T}$ mutations and factor $\mathrm{V}$ leiden was $10 \%$, normal cases were $27.5 \%$. The cases without MTHFR C 677Tgene mutations were $47.5 \%$. While The cases with MTHFR C 677 T mutations were 52.5\%. Heterozygous MTHFR C 677 T mutations cases were $37.5 \%$, homozygous cases were $15 \%$. The cases without Factor V Leiden gene mutations were $70 \%$, cases with Factor V Leiden mutations were $30 \%$. All cases with Factor V Leiden mutations were heterozygous and there was no homozygous cases. Conclusion: MTHFR mutation is highly expected in late first trimester missed abortions in primigravida specially the heterotype so significantly affect the pregnancy adversely while FACTOR V LEIDEN mutation is less likely to be found.
\end{abstract}

\section{INTRODUCTION}

Pregnancy is a hypercoagulable state secondary to an increase in coagulation factors, a reduction in naturally occurring anticoagulants, and impairment of fibrinolysis. The evolutionary advantage of these changes is thought to be stabilization of hemochorial placentation and reduction in post-partum blood loss. ${ }^{(1)}$

Since 1965 substantial progress has been made in the identification and understanding of inherited hypercoagulable disorders that promote thrombosis, collectively termed inherited thrombophilia. These include the factor V Leiden (FVL), methylenetetrahydrofolate reductase (MTHFR), and prothrombin mutations. ${ }^{(2)}$

Although thrombophilia was initially linked to various pregnancy outcomes, most accepted associations have been refuted. The American College of obstetricians and gynecologists (2013) believes that there is not a definitive causal link between these thrombophilia and adverse pregnancy outcomes in general, and abortion in particular. ${ }^{(3)}$

Pregnancy losses were divided into preclinical, first trimester clinical, and second trimester. A meaningfully increased rate of preclinical pregnancy failure in Leiden mutation carriers was found than in no activated 
protein $\mathrm{C}$ deficiency patients. ${ }^{(4)}$

The FVL and prothrombin-gene mutations are independent risk factors for venous thrombosis; it is debate whether a mutation in the gene encoding MTHFR, an enzyme involved in homocysteine metabolism, A study revealed that increases the risk of venous thrombosis. The relative risks of late fetal loss in carriers of factor $\mathrm{V}$ were 3.2. Thirteen percent of the women whose fetuses died and 20 percent of the control women were homozygous for the mutation in the MTHFR gene. ${ }^{(5)}$

FVL carriage has consistently been shown to increase the risk of early-onset gestational hypertension and HELLP syndrome (Hemolysis, Elevated Liver enzymes, low platelets) in pregnancy. Maternal carriage of FVL is also associated with severe placental abruption and fetal growth disturbance. ${ }^{6}{ }^{6}$

Pro-thrombophilic factors have also been proposed as one of the major causes of recurrent miscarriage (RM). In fact, some genetic polymorphisms of prothrombin (FII G 20210A), Factor FVL, and MTHFR, C677T genes were strongly associated with RM. These factors of inherited thrombophilia disturb normal placental vascularization and development leading to fetal growth restrictions, pregnancy failure, placental abruption, and therefore miscarriages or stillbirth. ${ }^{(7)}$

Another cause of miscarriages is inherited thrombophilia following damage to the maternal factor $\mathrm{V}$ gene G1691A (Leiden mutation) and prothrombin gene (G20210A mutation). These alterations are well studied and the test is part of the routine diagnostics of recurrent miscarriages. In the case of factor $\mathrm{V}$, both the Leiden mutation G1691A and the T1328C mutation appear to be important in the pathogenesis of RM, mainly in cases observed before the $7^{\text {th }}$ week of gestation. ${ }^{(8)}$

The most common causes of inherited thrombophilia are polymorphisms in genes encoding factor V, prothrombin (factor II), factor VII, MTHFR, and plasminogen activator inhibitor, while protein C, protein S and ant thrombin deficiency is less common. ${ }^{(9)}$

The finding of a link between FVL carrier state and early RPL would have significant implications for clinical practice, as it would provide a scientific rationale for screening for FVL mutation and targeted thromboprophylaxis in affected women. ${ }^{(10)}$

\section{MATERIALS AND METHODS}

a. Study population: This study was carried out on 40 primigravida pregnant females who attended the Antenatal Clinic at Elshatby Maternity University Hospital, Alexandria. The age of subjects was above 18 years and below 35 years. All subjects had missed abortion from the $7^{\text {th }}$ week +1 day to the $13^{\text {th }}$ week +6 days with a history of positive fetal cardiac activity that had stopped suddenly.

b. Methods: All the patients in the study were subjected to the following: detailed history taking, thorough clinical examination, ultrasound for fetal viability and gestational age, and finally, blood samples were collected from all pregnant women enrolled in the study for DNA extraction, and genotype analysis. FVL and MTHFR gene mutations were assayed based on polymerase chain reaction (PCR) and reversehybridization. The frequency of homozygous and heterozygous gene mutations, as well as, the co-expression of mutations was determined. The procedure includes three steps: (1) DNA isolation, (2) PCR amplification using biotinylated primers, (3) hybridization of amplification products to a test strip containing allele-specific oligonucleotide probes immobilized as an array of parallel lines. The assays covered two mutations: FV G1691A (Factor V Leiden Kit Roche ${ }^{\circledR}$ ), and MTHFR C677T (DiaplexQ MTHFR genotyping Kit ${ }^{(\mathrm{r})}$ ). The kit for FV-PTH-MTHFR Strip Assay was purchased from ViennaLab Diagnostics GmbH Gaudenzdorfer Guertel 43-45 A-1120 Vienna, Austria.

c. Statistical analysis of the data: Data were fed to the computer and analyzed using IBM SPSS software package version 20.0. (Armonk, NY: IBM Corp) ${ }^{(11)}$ Qualitative data were described using the number and percent. Quantitative data were described using range (minimum and maximum), mean, standard deviation, median, and interquartile range (IQR).

\section{RESULTS}


In the present study, the mean age of patients was $24.23+-3.39$ years, (range $18.0-34.0 y e a r s$ ). The gestational age recorded by the ultrasound at the time of blood sampling ranged from 8.14 - 13.71 weeks with a mean of $10.91+-1.59$ weeks. All the laboratory test results are illustrated in Figure 1.

Figure 2 demonstrates the assessed prevalence of thrombophilia polymorphisms in the studied cases: according to MTHFR C 677 T mutations only, the prevalence was in 17 cases (42.5\%), while FVL mutation only prevalence was in 8 cases only $(20.0 \%)$. It was observed that $10 \%$ (4 cases) were combined MTHFR C $677 \mathrm{~T}$ and FVL mutation, while, $27.5 \%$. (11 cases) were normal.

The number of cases without MTHFR C $677 \mathrm{~T}$ gene mutations was 19 cases (47.5\%). While the number of cases with MTHFR C $677 \mathrm{~T}$ mutations was 21 cases (52.5\%). It was observed that 15 cases out of the 21 cases $(37.5 \%)$ with MTHFR C $677 \mathrm{~T}$ mutations were heterozygous. While 6 cases only out of the 21 cases (15\%) with MTHFR C 677T mutations were homozygous. The number of cases without FVL gene mutations was 28 cases $(70.0 \%)$. While the number of cases with FVL mutations was 12 cases (30.0\%). It was observed that all cases with FVL mutations were heterozygous $(37.5 \%)$, and there were no homozygous cases between the studied cases.

Regarding the distribution of the studied cases according to MTHFR gene mutation and gestational age by the US (Table 1): There was no case with MTHFR gene mutation between 7-8 weeks of gestations. While there were 4 cases with MTHFR gene mutation between 8-9 weeks of gestations (10\%), 3 cases were heterozygous and 1 case was homozygous. There were 5 cases with MTHFR gene mutation between 9-10 weeks of gestations (12.5\%), 3 cases were heterozygous and 2 cases were homozygous. While there were 2 cases with MTHFR gene mutation between 10-11 weeks of gestations $(5 \%)$ and both were heterozygous. There was there were 6 cases with MTHFR gene mutation between 11-12 weeks of gestations (15\%), 4 cases were heterozygous and 2 cases were homozygous. While there were 2 cases with MTHFR gene mutation between 12-13 weeks of gestations (5\%) and both were heterozygous. Finally, there were 2 cases with MTHFR gene mutation between 13-14 weeks of gestations (5\%) and 1 case was heterozygous and the other was homozygous.

Regarding the distribution of the studied cases according to FVL gene mutation and gestational age by the US (Table 2): There was no case with homozygous FVL mutation in the studied cases. There was no case with FVL gene mutation in the studied cases between 7-8 weeks of gestations. While there was one case with FVL gene mutation between 8-9 weeks of gestations, and one case between 9-10 weeks of gestations (2.5 $\%)$ for both. There was there were two cases with FVL gene mutation between 10-11 weeks of gestations $(5$ $\%$ ), and 3 cases were between 11-12 weeks of gestations (7.5\%). While there were 2 cases with FVL gene mutation between 12-13 weeks of gestations (5\%), and 3 cases were between 13-14 weeks of gestations (7.5 $\%)$.

Comparison between MTHFR and FVL showed that there was about 19 case with no gene mutation related to MTHFR while about 28 cases with normal FVL so cases with normal study related to FVL more than case related to MTHFR. There were about 15 heterozygous cases of MTHFR gene mutation which more than heterozygous cases with FVL which was about 12 cases. There was no case with homozygous mutation related to FVL while was there about 6 cases with homozygous related to MTHFR gene mutation. There was a significant statistical difference between MTHFR and FVL with $\mathrm{p}$ vale $=0.022^{*}$.

The relation between MTHFR and FVL revealed that there were about 11 cases with no MTHFR or FVL gene mutation. There were 11 cases of heterozygous gene mutation of MTHFR while normal FVL. There were 6 cases with homozygous gene mutation of MTHFR while normal FVL. There were 8 cases with heterozygous gene mutation of FVL while normal MTHFR gene. There were 4 cases with heterozygous gene mutations of both the MTHFR gene and FVL gene. There was no significant statistical difference between MTHFR and FVL with $\mathrm{p}$ vale $=00.168$

\section{DISCUSSION}

Pregnancy loss (PL) is a common medical problem among reproductive-age women. However, relatively few 
women having one pregnancy loss experience multiple or recurrent pregnancy loss. ${ }^{(12)}$ Maintaining a normal pregnancy requires a series of differential gene expressions. FVL and MTHFR gene mutations are suggested as being reasons for PL. ${ }^{(13)}$ A study by Rodger et al, ${ }^{(14)}$ addressed the association of inherited thrombophilia with PL in late primigravida, focusing on tests for FVL, and MTHFR. ${ }^{(14)}$ Associations between these heritable thrombophilia variants and other serious pregnancy complications have also been documented. The main underlying mechanisms seem to be inhibition of trophoblast differentiation/invasion, and thrombosis of the maternal side of the placenta resulting in placenta mediated pregnancy complications and fetal loss. ${ }^{(15)}$ However, the relation between thrombophilia associated gene mutations and the adverse obstetric outcome is controversial and data in the literature are inconsistent because of study heterogeneity, potential publication bias, and sequential testing. ${ }^{(16)}$

The present Cross-sectional study aimed to investigate the prevalence of thrombophilic gene mutations (FVL and MTHFR C $667 \mathrm{~T}$ ) with miscarriage in primigravida in the late first trimester in an attempt to identify candidates for anticoagulation to improve pregnancy outcome. This study was conducted on 40 primigravida pregnant women with missed abortion in the late first trimester. In the present study, the maternal age was between 18.0 and 34.0years, with a mean of $24.23+-3.39$ years. While the gestational age was between 8.14 - 13.71 weeks with a mean of $10.91+-1.59$ weeks. In our study, MTHFR C $667 \mathrm{~T}$ mutations were present in 21 cases out of 40 participating cases $(52.5 \%)$. Several studies ${ }^{(17-19)}$ reported increasing evidence for a pathogenetic role of MTHFR gene polymorphism C677T in early PL. On the other hand, other authors ${ }^{(20,21)}$ found a negative association stating that MTHFR polymorphisms do not carry any risk in pregnancy. The different inclusion criteria and the different ethnic backgrounds of the selected patients may have contributed to the contradictory results. According to FVL gene mutation, it was present in 12 cases out of 40 participating cases $(30 \%)$. There is a large and contradictory body of literature on the association between maternally inherited thrombophilia and recurrent miscarriage ${ }^{(16,22,23)}$. Although most ${ }^{(16,24,25)}$ but not all ${ }^{(26,27)}$ large prospective cohort studies have failed to establish a consistent association between inherited thrombophilia and early or late fetal loss. The case-control and retrospective cohort studies have generally reported a link between FVL heterozygosity and fetal loss after 10 weeks and particularly for nonrecurrent loss after 20 weeks ${ }^{(28-31)}$. This suggests that any association is limited to high-risk populations and is modest. Small case-control or retrospective cohort studies involving heterogeneous populations have frequently reported contradictory results, in part because of the influence of various confounders (e.g. age, obesity) that are often not analyzed appropriately. ${ }^{(29,31)}$

In our study, there were 4 cases with combined thrombophilia (10\%). Combined thrombophilia included FVL and MTHFR C677T only. The same results were reported by previous studies ${ }^{(17,32-34)}$ that identified combined thrombophilic defects in women with recurrent PL, both early and late. The study by Rozano-Gorelick et al, ${ }^{(32)}$ reported that combined thrombophilia exists when inherited and /or acquired prothrombotic factors are pooled and every combination carries a different risk of thrombosis. Furthermore, Sarig et al, ${ }^{(26)}$ proposed a scoring system for women with thrombophilia based on four major categories: obstetric history, previous thromboembolic events, family history of thrombosis or gestational vascular complications, and type of thrombophilia. Combined thrombophilia was given a high score and the total score is calculated by summing up the scores of the four categories. Based upon the score achieved, the pregnancy risk for an individual woman may be stratified into four levels of risk: low [?]5, intermediate (score 6-10), high (score 11-14), and extremely high (score[?] 15). Finally, the number of homozygous and heterozygous individuals were assessed for each of the gene mutations studied. No homozygosity was detected in cases with FVL gene mutation cases. However, 6 cases out of 21 cases of MTHFR gene mutation were homozygous $(15 \%)$. A study by Couto et al, ${ }^{(35)}$ reported a low prevalence of homozygotes for FVL and stated that the prothrombotic tendency during pregnancy and the risk of thromboembolic events is increased with antithrombin deficiency and homozygous FVL as single traits. In fact, the reported prevalence in the general population of FVL homozygotes is less than $1 \%$ with a $2-4 \%$ risk of venous thromboembolism (VTE) per pregnancy increasing to around $17 \%$ in women with a previous history of VTE. ${ }^{(36,37)}$ Hence, our study and other studies reported an association between some types of thrombophilia and early miscarriage, but the absolute risk is small and varies considerably among reports. However, most large prospective cohort studies 
have failed to establish a consistent association between inherited thrombophilias and adverse pregnancy outcomes. According to recent evidence, screening for inherited thrombophilia in women with a history of recurrent or nonrecurrent fetal loss, abruption, intrauterine growth restriction, or preeclampsia is not recommended. ${ }^{(38)}$ Moreover, there is mounting evidence that the administration of prophylactic anticoagulation during pregnancy for the prevention of placenta- mediated pregnancy complications does not improve pregnancy outcome in affected patients. ${ }^{(39)}$

\section{CONCLUSION}

The prevalence of FVL mutations in our study did not appear significantly affect abortion in primigravida. MTHFR C667T mutations prevalence were appeared significantly have a relation to abortion. There was no significant increase in the prevalence of combined thrombophilia (Factor V Leiden and MTHFR C677T). The association between combined thrombophilia and abortion did not involve prothrombin gene G20210A mutations in the patient group. No homozygosity gene mutation was detected in the factor V patient group. Heterozygotes were significantly increased in the patient group compared to homozygotes for each of the two gene mutations studied. There is an association between some types of thrombophilia and miscarriage, but the absolute risk is small and varies considerably among reports.

Disclosure of interests: No potential competing financial, personal, political, intellectual, or religious interests were reported by the authors.

Author contributions: DE designed the study and performed data collection and analysis. MR interpreted and supervised the Lab analysis results. NE and NH supervised the clinical examinations and US findings. DE wrote the manuscript.All authors were involved in the revision of the manuscript.

Details of ethics approval: The clinical research study was approved by the Institutional Review Board (IRB) of Alexandria university hospital on 16 May 2019 with reference number 0105983. Informed consent was obtained before participation from patients or patient guardians in the case of incompetent patients.

Funding: This research received no specific grant from any funding agency.

\section{REFERENCES}

1. Jivraj S, Rai R, Underwood J, Regan L. Genetic thrombophilic mutations among couples with recurrent miscarriage. Hum Reprod. 2006;21(5):1161-5.

2. Ormesher L, Simcox L, Tower C, Greer IA. Management of inherited thrombophilia in pregnancy. Womens Health (Lond). 2016;12(4):433-41.

3. Cunningham FG. ea Williams Obstetrics. 24th ed: McGraw-hill Education; 2014. p. 350-75.

4. Alhalaki W, Altanoukhi IA, Alhalabi M. The association of activated protein C resistance (aPCR) with recurrent pregnancy loss in syrian population. Inter J Pharma Sci Rev Res. 2016;38(151):290-5.

5. D’Uva M, Di Micco P, Strina I, Ranieri A, Alviggi C, Mollo A, et al. Etiology of hypercoagulable state in women with recurrent fetal loss without other causes of miscarriage from Southern Italy: new clinical target for antithrombotic therapy. Biologics. 2008;2(4):897-902.

6. Bloomenthal D, von Dadelszen P, Liston R, Magee L, Tsang P. The effect of factor V Leiden carriage on maternal and fetal health. Cmaj. 2002;167(1):48-54.

7. Turki RF, Assidi M, Banni HA, Zahed HA, Karim S, Schulten HJ, et al. Associations of recurrent miscarriages with chromosomal abnormalities, thrombophilia allelic polymorphisms and/or consanguinity in Saudi Arabia. BMC Med Genet. 2016;17(Suppl 1):69.

8. Kacprzak M, Chrzanowska M, Skoczylas B, Moczulska H, Borowiec M, Sieroszewski P. Genetic causes of recurrent miscarriages. Ginekol Pol. 2016;87(10):722-6. 
9. Wolski H, Barlik M, Drews K, Klejewski A, Kurzawińska G, Ożarowski M, et al. Contribution of inherited thrombophilia to recurrent miscarriage in the Polish population. Ginekol Pol. 2017;88(7):385-92.

10. Sergi C, Al Jishi T, Walker M. Factor V Leiden mutation in women with early recurrent pregnancy loss: a meta-analysis and systematic review of the causal association. Arch Gynecol Obstet. 2015;291(3):671-9.

11. Kirkpatrick LA, Feeney BC. A simple guide to IBM SPSS statistics for version 20.0. Student ed. Belmont, Calif.: Wadsworth, Cengage Learning; 2013.

12. Christiansen OB, Steffensen R, Nielsen HS, Varming K. Multifactorial etiology of recurrent miscarriage and its scientific and clinical implications. Gynecol Obstet Invest. 2008;66(4):257-67.

13. Park WC, Chang JH. Clinical Implications of Methylenetetrahydrofolate Reductase Mutations and Plasma Homocysteine Levels in Patients with Thromboembolic Occlusion. Vasc Specialist Int. 2014;30(4):113-9.

14. Rodger MA, Paidas M, McLintock C, Middeldorp S, Kahn S, Martinelli I, et al. Inherited thrombophilia and pregnancy complications revisited. Obstet Gynecol. 2008;112(2 Pt 1):320-4.

15. Poppe K, Velkeniers B, Glinoer D. The role of thyroid autoimmunity in fertility and pregnancy. Nat Clin Pract Endocrinol Metab. 2008;4(7):394-405.

16. Dizon-Townson D, Miller C, Sibai B, Spong CY, Thom E, Wendel G, Jr., et al. The relationship of the factor V Leiden mutation and pregnancy outcomes for mother and fetus. Obstet Gynecol. 2005;106(3):51724.

17. Micco PD, D'Uva M. Recurrent pregnancy loss and thrombophilia. Open Atherosclerosis \& Thrombosis J 2009;2(1):33-5.

18. Lissak A, Sharon A, Fruchter O, Kassel A, Sanderovitz J, Abramovici H. Polymorphism for mutation of cytosine to thymine at location 677 in the methylenetetrahydrofolate reductase gene is associated with recurrent early fetal loss. Am J Obstet Gynecol. 1999;181(1):126-30.

19. Wouters MG, Boers GH, Blom HJ, Trijbels FJ, Thomas CM, Borm GF, et al. Hyperhomocysteinemia: a risk factor in women with unexplained recurrent early pregnancy loss. Fertil Steril. 1993;60(5):820-5.

20. Makino A, Nakanishi T, Sugiura-Ogasawara M, Ozaki Y, Suzumori N, Suzumori K. No association of C677T methylenetetrahydrofolate reductase and an endothelial nitric oxide synthase polymorphism with recurrent pregnancy loss. Am J Reprod Immunol. 2004;52(1):60-6.

21. Ren A, Wang J. Methylenetetrahydrofolate reductase C677T polymorphism and the risk of unexplained recurrent pregnancy loss: a meta-analysis. Fertil Steril. 2006;86(6):1716-22.

22. Silver RM, Zhao Y, Spong CY, Sibai B, Wendel G, Jr., Wenstrom K, et al. Prothrombin gene G20210A mutation and obstetric complications. Obstet Gynecol. 2010;115(1):14-20.

23. Rodger MA, Hague WM, Kingdom J, Kahn SR, Karovitch A, Sermer M, et al. Antepartum dalteparin versus no antepartum dalteparin for the prevention of pregnancy complications in pregnant women with thrombophilia (TIPPS): a multinational open-label randomised trial. Lancet. 2014;384(9955):1673-83.

24. Roque H, Paidas MJ, Funai EF, Kuczynski E, Lockwood CJ. Maternal thrombophilias are not associated with early pregnancy loss. Thromb Haemost. 2004;91(2):290-5.

25. Clark P, Walker ID, Govan L, Wu O, Greer IA. The GOAL study: a prospective examination of the impact of factor $\mathrm{V}$ Leiden and $\mathrm{ABO}(\mathrm{H})$ blood groups on haemorrhagic and thrombotic pregnancy outcomes. Br J Haematol. 2008;140(2):236-40.

26. Sarig G, Vidergor G, Brenner B. Assessment and management of high-risk pregnancies in women with thrombophilia. Blood Rev. 2009;23(4):143-7. 
27. Preston FE, Rosendaal FR, Walker ID, Briet E, Berntorp E, Conard J, et al. Increased fetal loss in women with heritable thrombophilia. Lancet. 1996;348(9032):913-6.

28. Yamada H, Kato EH, Kobashi G, Ebina Y, Shimada S, Morikawa M, et al. Recurrent pregnancy loss: etiology of thrombophilia. Semin Thromb Hemost. 2001;27(2):121-9.

29. Robertson L, Wu O, Langhorne P, Twaddle S, Clark P, Lowe GD, et al. Thrombophilia in pregnancy: a systematic review. Br J Haematol. 2006;132(2):171-96.

30. Said JM, Higgins JR, Moses EK, Walker SP, Borg AJ, Monagle PT, et al. Inherited thrombophilia polymorphisms and pregnancy outcomes in nulliparous women. Obstet Gynecol. 2010;115(1):5-13.

31. Bouvier S, Cochery-Nouvellon E, Lavigne-Lissalde G, Mercier E, Fabbro-Peray P, Balducchi JP, et al. Comparative incidence of pregnancy outcomes in thrombophilia-positive women from the NOH-APS observational study. Blood. 2014;123(3):414-21.

32. Rozano-Gorelick A, Papadakis E, Brenner B. Combined thrombophilia and obstetric complications. Open Atheroscl Thromb J. 2009;2(1):38-41.

33. Raziel A, Kornberg Y, Friedler S, Schachter M, Sela BA, Ron-El R. Hypercoagulable thrombophilic defects and hyperhomocysteinemia in patients with recurrent pregnancy loss. Am J Reprod Immunol. 2001;45(2):65-71.

34. Coulam CB, Jeyendran RS, Fishel LA, Roussev R. Multiple thrombophilic gene mutations rather than specific gene mutations are risk factors for recurrent miscarriage. Am J Reprod Immunol. 2006;55(5):360-8.

35. Couto E, Nomura ML, Barini R, Pinto e Silva JL. Pregnancy-associated venous thromboembolism in combined heterozygous factor V Leiden and prothrombin G20210A mutations. Sao Paulo Med J. 2005;123(6):2868.

36. Zotz RB, Gerhardt A, Scharf RE. Inherited thrombophilia and gestational venous thromboembolism. Best Pract Res Clin Haematol. 2003;16(2):243-59.

37. Lockwood CJ, Bauer KA. Inherited thrombophilias in pregnancy. UpToDate. 2016.

38. Bates SM, Greer IA, Middeldorp S, Veenstra DL, Prabulos AM, Vandvik PO. VTE, thrombophilia, antithrombotic therapy, and pregnancy: Antithrombotic Therapy and Prevention of Thrombosis, 9th ed: American College of Chest Physicians Evidence-Based Clinical Practice Guidelines. Chest. 2012;141(2 Suppl):e691S-e736S.

39. Bujold E, Gouin K, Cote S. Low-molecular-weight heparin added to aspirin in the prevention of recurrent early-onset pre-eclampsia in women with inheritable thrombophilia: the FRUIT-RCT: a rebuttal. J Thromb Haemost. 2012;10(6):1195; author reply 6.

Figures and Tables 

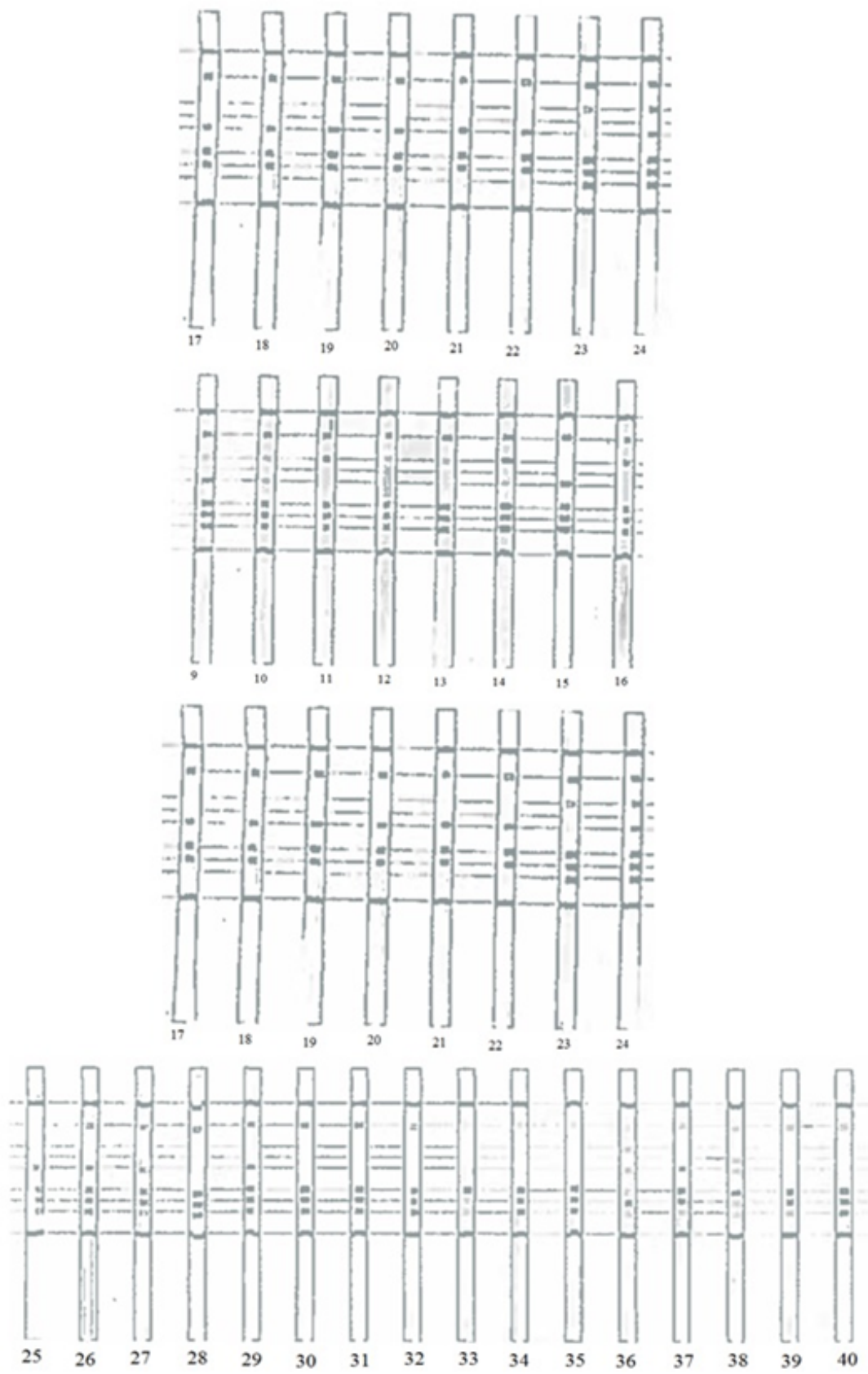

Fig. 1. The results of laboratory tests 


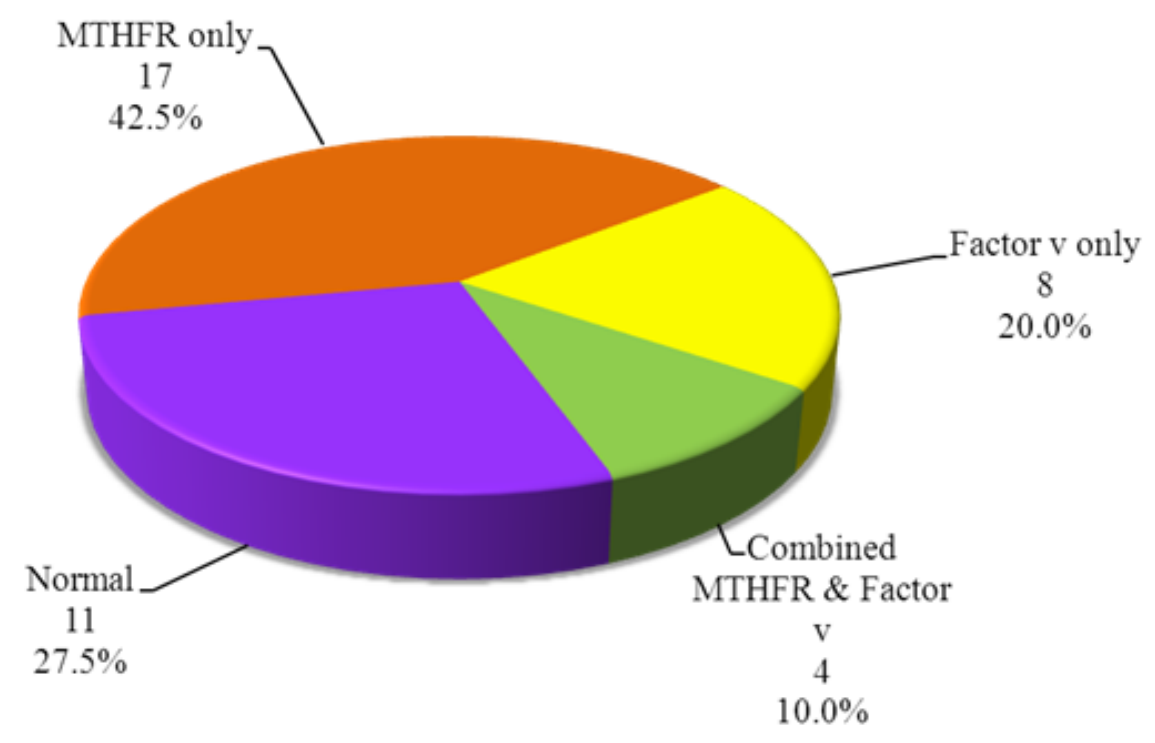

Fig. 2. Distribution of the studied cases according to MTHFR \& factor V $(\mathrm{n}=40)$

Table (1): Distribution of the studied cases according to MTHFR and gestational age by the US $(n=40)$

\begin{tabular}{lllllllll}
\hline US & MTHFR & MTHFR & MTHFR & MTHFR & MTHFR & MTHFR & $\chi^{\mathbf{2}}$ & ${ }^{\text {MC }_{\mathbf{p}}}$ \\
\hline & Normal & Normal & Heterozygous & Heterozygous & Homozygous & Homozygous & \\
& No. & $\mathbf{9}$ & No. & $\mathbf{\%}$ & No. & $\mathbf{\%}$ & \\
$7 \mathrm{w}-8 \mathrm{w}$ & 0 & 0.0 & 0 & 0.0 & 0 & 0.0 & - & - \\
$8 \mathrm{w}-9 \mathrm{w}$ & 1 & 2.5 & 3 & 7.5 & 1 & 2.5 & 2.076 & 0.340 \\
$9 \mathrm{w}-10 \mathrm{w}$ & 4 & 10.0 & 3 & 7.5 & 2 & 5.0 & 0.733 & 0.777 \\
$10 \mathrm{w}-11 \mathrm{w}$ & 2 & 5.0 & 2 & 5.0 & 0 & 0.0 & 0.639 & 1.000 \\
$11 \mathrm{w}-12 \mathrm{w}$ & 5 & 12.5 & 4 & 10.0 & 2 & 5.0 & 0.340 & 1.000 \\
$12 \mathrm{w}-13 \mathrm{w}$ & 4 & 10.0 & 2 & 5.0 & 0 & 0.0 & 1.176 & 0.602 \\
$13 \mathrm{w}-14 \mathrm{w}$ & 3 & 7.5 & 1 & 2.5 & 1 & 2.5 & 1.037 & 0.679 \\
Total & $\mathbf{1 9}$ & $\mathbf{4 7 . 5}$ & $\mathbf{1 5}$ & $\mathbf{3 7 . 5}$ & $\mathbf{6}$ & $\mathbf{1 5 . 0}$ & & \\
\hline
\end{tabular}

2: Chi-square test MC: Monte Carlo

p: p-value for comparing between the three categories

Table (2): Distribution of the studied cases according to factor V Leiden $(n=40)$

\begin{tabular}{lllllll}
\hline Ultrasound & Factor V Leiden & Factor V Leiden & Factor V Leiden & Factor V Leiden & Factor V Leiden & F \\
& Normal & Normal & Heterozygous & Heterozygous & Homozygous & F \\
& No. & $\%$ & No. & $\%$ & No. & 0 \\
$7 \mathrm{w}-8 \mathrm{w}$ & 0 & 0.0 & 0 & 0 & 0 & 0 \\
$8 \mathrm{w}-9 \mathrm{w}$ & 4 & 10.0 & 1 & 2.5 & 0 & 0 \\
$9 \mathrm{w}-10 \mathrm{w}$ & 8 & 20.0 & 1 & 2.5 & 0 & 0 \\
$10 \mathrm{w}-11 \mathrm{w}$ & 3 & 7.5 & 2 & 5 & 0 & 0 \\
$11 \mathrm{w}-12 \mathrm{w}$ & 8 & 20.0 & 3 & 7.5 & 0 & 0
\end{tabular}




\begin{tabular}{lllllll}
\hline Ultrasound & Factor V Leiden & Factor V Leiden & Factor V Leiden & Factor V Leiden & Factor V Leiden & F \\
\hline $12 \mathrm{w}-13 \mathrm{w}$ & 3 & 7.5 & 2 & 5 & 0 & 0 \\
$13 \mathrm{w}-14 \mathrm{w}$ & 2 & 5.0 & 3 & 7.5 & 0 & 0 \\
Total & $\mathbf{2 8}$ & $\mathbf{7 0 . 0}$ & $\mathbf{1 2}$ & $\mathbf{3 0 . 0}$ & $\mathbf{0}$ & $\mathbf{0}$ \\
\hline
\end{tabular}

2: Chi-square test FE: Fisher Exact

p: p-value for comparing between the three categories 